\title{
Modelling Block Laying Productivity on Building Sites in Kampala
}

\author{
"Allan Dickens Ouga', Henry Mwanaki Alinaitwe ${ }^{2}$ and \\ Godfrey Mwesige!
}

Published online: 15 July 2020

To cite this article: Allan Dickens Ouga, Henry Mwanaki Alinaitwe and Godfrey Mwesige (2020). Modelling block laying productivity on building sites in Kampala. Journal of Construction in Developing Countries, 25(1): 109-128. https://doi. org/10.21315/jcdc2020.25.1.6.

To link to this article: https://doi.org/10.21315/jcdc2020.25.1.6

\begin{abstract}
Block laying productivity is an important factor in planning, scheduling and control of labour-intensive building projects with significant bearing on project cost and delays. Despite the wide application of block laying on building projects in Uganda, no study has modelled the productivity of block layers in terms of work output in comparison with individual attributes of block layers. This article explores the modelling of block laying productivity on building sites in Kampala based on an individual block layer's attributes and work environment. The data was collected using a specially designed measurement sheet filled on-site and a survey questionnaire to collect data on personal attributes of block layers from 40 building sites. In the estimated regression model, work height, number of porters per block layer and a combination of education and experience were significant at $95 \%$ confidence level. The results further show that neither education nor experience alone is important in explaining a block layer's productivity. Based on the results, it is clear that an experienced and educated block layer yields higher block laying productivity, which is important for project planning applications. These results are limited to building sites in Kampala, work heights not exceeding $6 \mathrm{~m}$ above ground level and $400 \mathrm{~mm} \times 225 \mathrm{~mm} \times 200 \mathrm{~mm}$ blocks.
\end{abstract}

Keywords: Block laying, Productivity, Building sites, Regression modelling

\section{INTRODUCTION}

The construction industry in all parts of the world is strategic to the national economy providing infrastructure and shelter that support various social, economic and industrial functions (Chigara and Moyo, 2014). Thus, the industry is a major factor in the drive for economic progress of a nation (Kuroshi, 2014). Uganda's construction industry contributes over $12 \%$ of Uganda's gross domestic product (Uganda National Commission for UNESCO, 2013). Recent statistics showed an increase of price index for the whole construction sector (covering material prices, wage rates and equipment hire) by $5.7 \%$ in the year ended June 2016 compared to the year ended June 2015 (Uganda Bureau of Statistics, 2016). Despite the impressive performance of Uganda's construction industry over the past 20 years, the construction sector is perceived as a low-productivity sector because of low technology image and employment of a large number of mainly unskilled workers (Alinaitwe et al., 2007). Therefore, particular attention should be drawn towards labour productivity as

\footnotetext{
'Department of Construction Economics and Management, College of Engineering, Design, Art and Technology, Makerere University, P.O. Box 7062, Kampala, UGANDA

${ }^{2}$ Department of Architecture and Physical Planning, College of Engineering, Design, Art and Technology, Makerere University, P.O. Box 7062, Kampala, UGANDA

"Corresponding author: dickens.allan@gmail.com
} 
an important sector component. Hence research to benchmark block layers' productivity, identify its main challenges and proposing strategies to match it with the wage rates is inevitable (Mostafa and Khaled, 2011).

A nation's periods of prosperity are usually associated with high levels of construction output expressed in terms of unit productivity (Irumba, 2014). Labour productivity (i.e. the output per worker) is a critical measure of such output from project to industry and national levels. A study by Alinaitwe et al. (2007) noted that poor productivity of construction workers at the project level is one of the most daunting problems faced by construction industries in developing countries. Hence, a need to examine in detail productivity at the project level and factors that influence it. Several studies in the literature have been conducted on factors influencing the productivities of construction workers in general (Alinaitwe et al., 2007; Hafez et al., 2014). However, none of these studies is specific on modelling productivity of block laying for project planning and control applications yet blocks are increasingly becoming the main material for building walls on medium and high-value building projects in Uganda.

Block laying is a laborious activity in developing countries which represents one of the most significant risks to contractors in Uganda's competitive construction market because their productivities are not documented (Alinaitwe et al., 2007). As a result, Uganda's construction industry has been shown to suffer delays and cost overruns due to poor labour productivity (Apolot, 2009). This article, therefore, presents the findings of a study on determining the productivity of block layers taking into account work height and environmental factors as well as individual attributes of a block layer at project level on building projects in Kampala. The article further discusses model development and estimation of individual block layer's productivity measured in terms of area of blockwork output per hour. The rest of the article comprises of the following major sections: definition of labour productivity based on the literature, followed by methods and materials used in the study, presentation of results, discussion of results, conclusion and recommendation for future research and lastly references.

\section{LABOUR PRODUCTIVITY}

Productivity is referred to as either the ratio of output to input or the effective utilisation of resources (inputs) in producing goods and/or services (output) (Thomas and Sudhakumar, 2014). Nalumansi and Mwesige (2011) defined productivity as the output per person, machine or organisation per given time and can be measured in units of product, number of customers, or any other measure that a business might prefer to use. Productivity together with cost and quality are traditionally identified as the three main critical success factors for a construction project (Sweis et al., 2009).

Good construction management, therefore, strives to devise methods that boost productivity so as to reduce project duration, cost and improve profitability (Nalumansi and Mwesige, 2011 ). In the case of block laying works, productivity is a function of sq. $\mathrm{m}$ of walling built per payable unit time, day or hour, depending on what is agreed upon by the block layers and the employer. However, most commonly, the time unit in Uganda is eight hours a day (Nalumansi and Mwesige, $2011)$. 
Blocks are walling units exceeding in length, width or height the dimensions specified for bricks in BS EN 772-16 (Chudley and Greeno, 2010). According to BS 3921:1985 (now referred as BS EN 771-1), a block is defined as a masonry unit with overall dimensions exceeding $225 \mathrm{~mm}$ in length, $112.5 \mathrm{~mm}$ in thickness and its height shall not exceed either its length or six times its thickness. These definitions are silent on the maximum dimensions of the length and thickness of a block and differ from that of the Ministry of Works and Transport which specifies $450 \mathrm{~mm} \times 225 \mathrm{~mm}$ as a standard face size of a block to be used for walling in Uganda (Ministry of Works and Transport, 2012). It can be deduced from Chudley and Greeno (2010) that a block layer is a trained or skilled worker who builds with blocks, bricks or stones or concrete.

According to Thomas and Sudhakumar (2014), two measures of productivity commonly used in the construction industry are the total factor productivity (TFP) and partial factor productivity (PFP). TFP is defined as the ratio of total output to total input (Syverson, 2011 ), with the latter usually including labour, materials, equipment, energy and capital (as shown in Equation 1).

$$
\text { TFP }=\frac{\text { Total output }}{\sum(\text { Labour }+ \text { Materials }+ \text { Equipment }+ \text { Energy }+ \text { Capital })}
$$

The TFP measure comprises many variables which may be estimated inaccurately especially when records of the attributes become scanty. It is an elaborate method of calculating productivity which requires highly skilled personnel and more time.

The PFP is expressed as the ratio of the outputs to a single or selected set of inputs. PFP defines construction labour productivity as the ratio of output to labour input; the output is measured in terms of the quantities installed and labour input is measured as work-hours (Thomas and Sudhakumar, 2014). This method is brief and simple and hence can be recommended for on-site calculation of productivity as follows:

$$
\text { Labour productivity }=\frac{\text { Output quantity }}{\text { Labour hours }}
$$

Labour productivity is considered one of the best indicators of production efficiency and higher productivity levels usually translates into superior profitability (Thiyagu and Dheenadhayalan, 2015). However, studies over the years have identified a myriad of factors that affect construction labour productivity in both developing and developed countries such as Zimbabwe (Chigara and Moyo, 2014), Thailand (Makulsawatudom and Emsley, 2001; Srinavin and Mohamed, 2003), Uganda (Alinaitwe et al., 2007; Nalumansi and Mwesige, 2011), Egypt (Hafez et al., 2014), Kentucky (Dai, Goodrum and Maloney, 2009) and Hong Kong (Ng et al., 2004). However, none of the studies provides a detailed account of the impact of the labourer's attributes to his/her productivity.

A previous study by Muhammad and Rosli (2016) singled out site layout planning as the only factor with a significant impact on productivity on construction sites, leaving out the impact of labourers' attributes and many other environmental factors on such productivity that can be optimised during resource allocation and planning. Another study by Florin et al. (2017) on labour productivity forecast did not take into account productivity at the microlevel but rather at the national level 
as the case is in the current study. Jang et al.'s (2011) labour productivity model concluded that the work management component (i.e. the manager's abilities) and the work technique component (i.e. work continuity) had a greater impact on productivity than the worker's capability, which was not investigated in detail. The model has a limitation of focusing on the qualitative perspective of the site managers on labour productivity than individual block layers. However, no model was developed to predict productivity, which is a major contribution to this study.

On ways of improving labour productivity in developing countries, Alinaitwe (2008) concluded that education and level of experience of workers were important for overall productivity. Thiyagu and Dheenadhayalan (2015) asserted that effective allocation of limited resources, proving workers with better support and increasing workers' motivation are the ways of improving labour productivity.

\section{METHODS AND MATERIALS}

The presentation in this article gives the findings of a research effort that investigated the productivity of block layers on building sites in Kampala. Specifically, the study set out to (1) determine the common sizes and coverage rates of concrete blocks used in building in Kampala, (2) establish the productivity of block layers at different wall heights on-site and (3) develop models to predict the productivity of block laying per block layer per hour on building sites.

\section{Research Design}

The study was quantitative involving on-site measurements of work done per hour and specific attributes of individual block layers. On-site observations and measurement of the productivity of block layers, measurement of block sizes from manufacturers and sites, rating factors that affect block layers' productivities over three months was quantitative. Both qualitative and quantitative research approaches were adopted for measuring productivity and determining factors that influence the productivity of individual block layers. Quantitative data were collected using a specially designed measurement sheet administered directly on-site by the researchers. A survey questionnaire was equally designed and administered to block layers to assess the factors deemed to affect productivity considering experience and level of education. The data were then summarised and analysed using computer programs namely Statistical Package for the Social Sciences (SPSS 16.0), Microsoft Excel and RStudio interface for R software. Summary statistical data were prepared for productivity namely mean, standard deviations and coefficient of variation. RStudio modelling software was used to estimate a model predicting productivity of block laying per block layer per hour using a vector of explanatory variables, namely wall height, number of porters, a combination of experience and level of education of a block layer. Note that the distance between material heaps and work station was not explored in the current study although site observations showed that materials (blocks and mortar mixing) was on average within $5 \mathrm{~m}$ to the work area.

A PFP measure of productivity (i.e. ratio of output to labour hours) was chosen due to its brief and simpler use for on-site productivity calculation as opposed to the laborious TFP measure which expresses productivity as a ratio of total output to a summation of labour, materials, equipment, energy and capital (Thomas and 
Sudhakumar, 2014). Block laying output was considered as the sq. m of blockwork built per mason while labour hours was the time taken by the block layer to build the specified area of blockwork.

\section{Data Collection Tools and Methods}

Productivities of at least 160 block layers obtained basing on Green (1991) rule of thumb, $N \geq 50+8 p$, for the multiple correlations between criterion $(N)$ and predictors (p) were studied. The same approach to sample size for regression modelling has recently been applied by Voorhis and Morgan (2007) and similarly adopted in this study. Forty building sites at block laying operations within Kampala Capital City were selected as study areas for block layers' daily productivities and block size measurements. Building sites were chosen because blocks are the main wall construction units, especially in public building projects as clay bricks increasingly become rare, expensive and environmentally destructive. Dimensions of concrete blocks used and daily measurements of block layers' output were recorded on building sites. Daily quantities of blockwork built by each block layer on-site were measured in sq. $\mathrm{m}$. Each of the study building sites had a research assistant to observe and record block sizes and quantities of individual block layer output in specially designed measurement sheet. The measurement sheet comprised these major parts: the name of the site, block layer's name/code, block size, the number of porters, block layer's level of education, block layer's experience, start time to lay blocks, rest interval (s), end time to lay blocks, area of wall built (measured using a handheld tape measure) and work height which is the middle value of the wall height range (a sample measurement sheet including qualitative and quantitative data fields is appended).

\section{RESULTS}

\section{Model Block Sizes on Building Sites}

Measurements of dimensions of concrete blocks on building and manufacturing sites including their respective coverage rates showed that the commonly used blocks on sites are $400 \mathrm{~mm} \times 150 \mathrm{~mm} \times 200 \mathrm{~mm}$ and $400 \mathrm{~mm} \times 225 \mathrm{~mm} \times 200 \mathrm{~mm}$ accounting for $32 \%$ and $27 \%$ of all the measured blocks, respectively. However, there were other sizes: $400 \mathrm{~mm} \times 100 \mathrm{~mm} \times 200 \mathrm{~mm}(10 \%), 400 \mathrm{~mm} \times 160 \mathrm{~mm} \times$ $200 \mathrm{~mm}(10 \%), 395 \mathrm{~mm} \times 190 \mathrm{~mm} \times 195 \mathrm{~mm}$ (5\%), $390 \mathrm{~mm} \times 190 \mathrm{~mm} \times 195 \mathrm{~mm}(1 \%)$, $400 \mathrm{~mm} \times 200 \mathrm{~mm} \times 230 \mathrm{~mm}(2 \%), 400 \mathrm{~mm} \times 200 \mathrm{~mm} \times 200 \mathrm{~mm}(5 \%), 410 \mathrm{~mm} \times$ $150 \mathrm{~mm} \times 180 \mathrm{~mm}(1 \%), 450 \mathrm{~mm} \times 100 \mathrm{~mm} \times 230 \mathrm{~mm}(1 \%), 400 \mathrm{~mm} \times 130 \mathrm{~mm} \times$ $200 \mathrm{~mm}$ (2\%), $400 \mathrm{~mm} \times 200 \mathrm{~mm} \times 250 \mathrm{~mm}$ (2\%), $395 \mathrm{~mm} \times 190 \mathrm{~mm} \times 190 \mathrm{~mm}(1 \%)$ and $395 \mathrm{~mm} \times 140 \mathrm{~mm} \times 190 \mathrm{~mm}$ (1\%). The dimensions of the block indicated are length $\times$ thickness $\times$ height in millimetres. The coverage rate (number of blocks per sq. $m$ of blockwork) for both sizes of common blocks is 11 . This result shows that so many block sizes are manufactured hence there is no control on the dimensions of blocks manufactured on building sites in Kampala. This affects standards and project management and control. There is a need for standardisation and control of manufacturing standards of concrete blocks. However, for the study of productivity, two predominant block sizes, $400 \mathrm{~mm} \times 225 \mathrm{~mm} \times 200 \mathrm{~mm}$ and 
$400 \mathrm{~mm} \times 150 \mathrm{~mm} \times 200 \mathrm{~mm}$, were considered while the $400 \mathrm{~mm} \times 150 \mathrm{~mm} \times$ $200 \mathrm{~mm}$ blocks were used in model development.

\section{Block Laying Productivities}

The summary descriptive statistics of measured productivities from 40 building sites are presented in Table 1. The $95 \%$ confidence intervals of the mean productivities at different wall heights are also given in Table 1. The overlap between any two levels shows that there is no statistically significant difference between the mean productivities of the levels or heights under comparison. The $95 \%$ confidence intervals presented in Table 1 do overlap for all heights and levels considered in the study. This shows that although the mean values vary by level and height, the difference is not statistically significant at $95 \%$ confidence level owing to high variability (high values of coefficient of variation) in productivities of an individual block layer working at different levels and heights. The results further show that on average, the productivity of a block layer irrespective of the block size is more than 1 sq. $\mathrm{m}$ per hour from plinth walls up to 2 to $3 \mathrm{~m}$ above ground floor slab level. However, productivity decreases above the first floor slab level for heavy blocks to less than $1 \mathrm{sq}$. $\mathrm{m}$ per hour. Figure 1 illustrates the mean productivities per block layer for different levels and heights. Despite the decrease in productivity with an increase in wall height regardless of the block size, the figure shows consistently lower mean values between 225 and $150 \mathrm{~mm}$ thick blocks for all levels and heights possibly attributable to differences in block weight.

\section{Block Laying Productivity Model Estimation}

The mean productivities of 83 block layers using a solid concrete block of size $400 \mathrm{~mm}$ $\times 225 \mathrm{~mm} \times 200 \mathrm{~mm}$ at wall heights ranging from the ground level up to $3 \mathrm{~m}$ above the first-floor slab and their attributes were recorded. The block size was chosen based on its being the common heaviest block in use in Kampala. For modelling purposes, the mid-height of a particular range was taken as representative height for the range in question, for example up to $1 \mathrm{~m}$ and 1 to $2 \mathrm{~m}$ height ranges, representative heights of 0.50 and $1.50 \mathrm{~m}$, respectively were used. Table 2 gives the summary statistics of the data used for model estimation. The data shows wider variability for all explanatory variables saves for the number of porters per block layer with almost 44 block layers out of 70 having two assigned porters. This lack of internal variability in data may affect the statistical significance of the variable in the model, even when a-priori expectation strongly suggests so. This is a major limitation in data for this variable arising out of practice in Kampala but model estimation included this variable as well because of the strong a-priori expectation that it contributes to increased productivity of a block layer in the labour-intensive construction industry. 


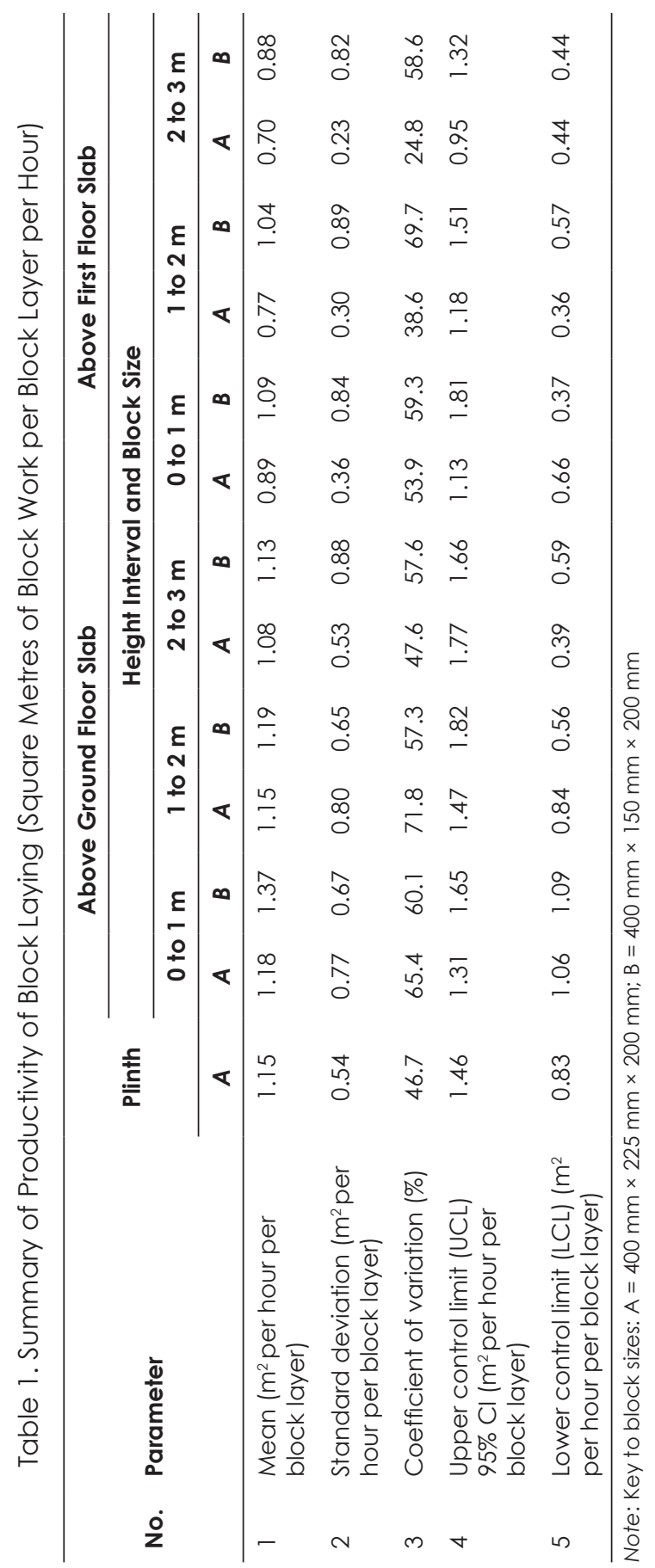


Allan Dickens Ouga et al.

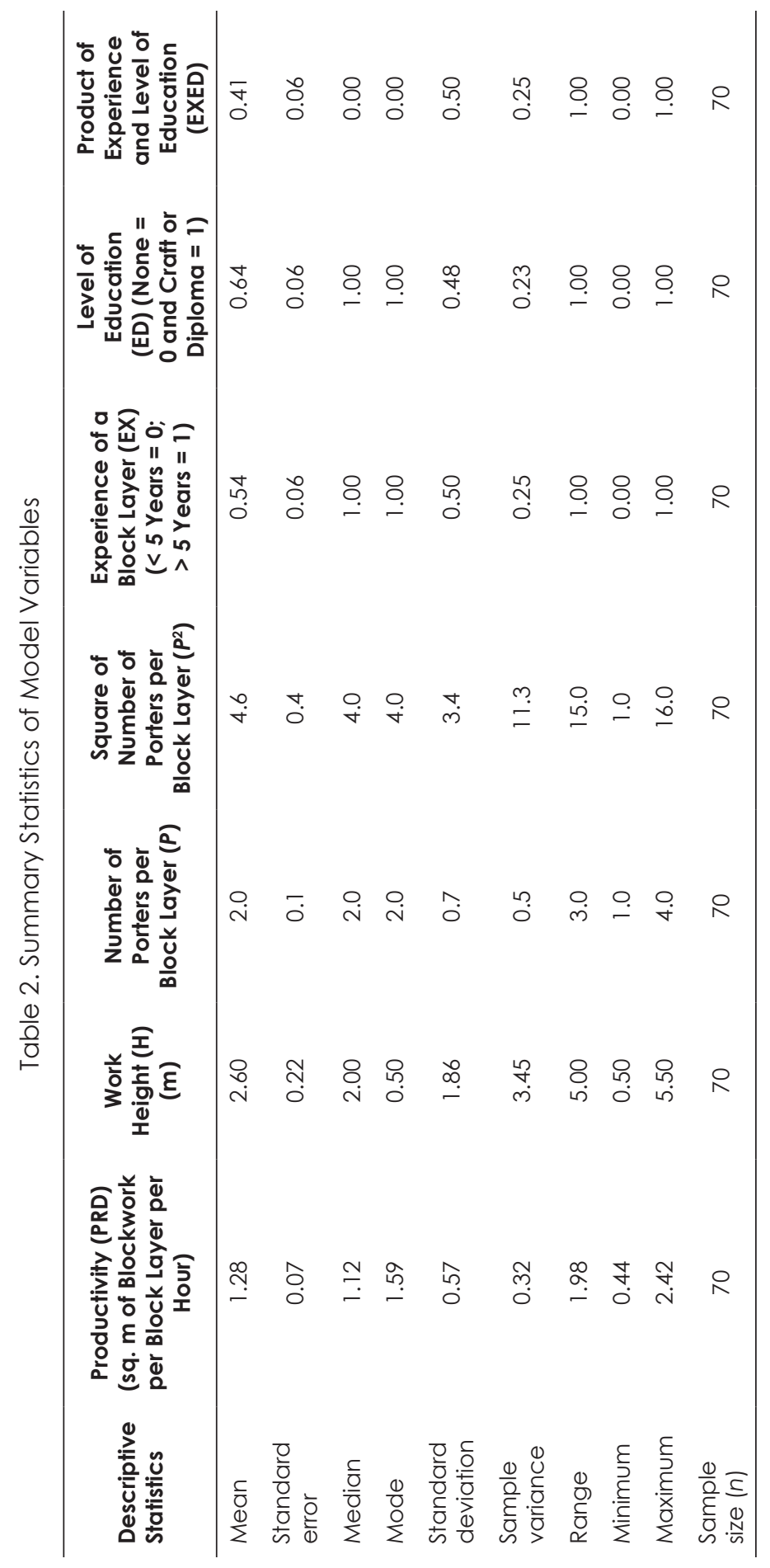

116/PENERBIT UNIVERSITI SAINS MALAYSIA 


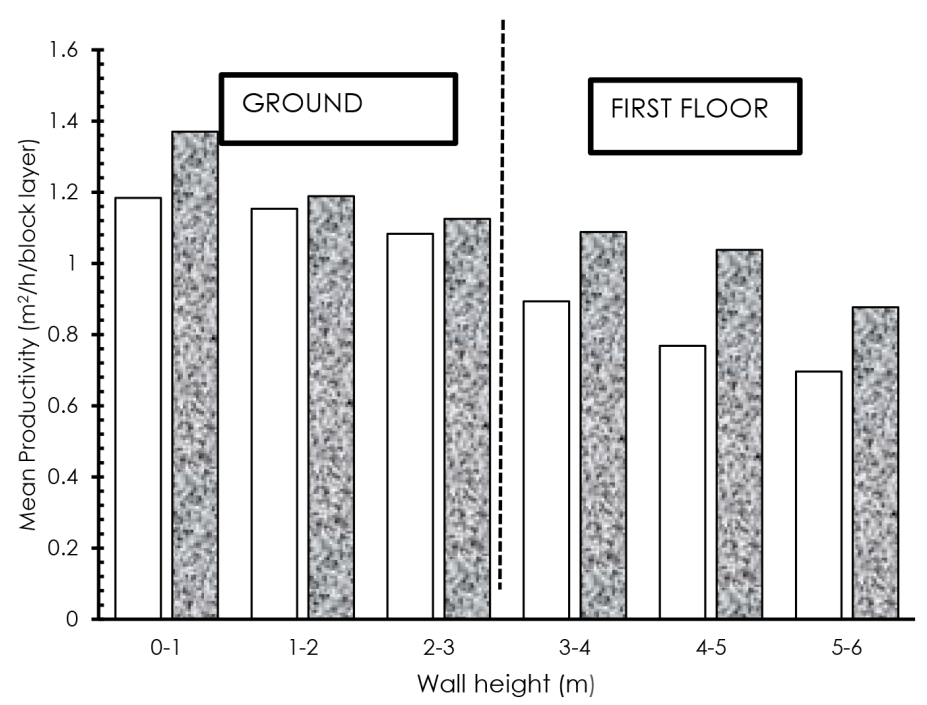

ㄴ225 mm thick block 미 $50 \mathrm{~mm}$ thick block

Figure 1. Measured Productivity Using Different Block Sizes

The six predictor variables with a theoretical bearing on block laying productivity were explored for significance during model estimation namely, the wall height, number of porters assigned to a block layer, years of experience, education level attained by a block layer, statistical interaction between years of experience and education level attained by a block layer and the second-order factor for the number of porters per block layer. There were two categorical variables used in the model: level of education of the block layer (none $=0$; craft or diploma $=1$ ) and experience of the block layer (less than five years $=0$; more than five years $=1$ ). The five-year threshold was chosen because most $(76 \%)$ block layers as per the data collected had at most five years' experience thus, the experience was either less or more than five years, making it a categorical variable.

Besides, model estimation included second-order variables based on theoretical a-priori expectations between the response and subject explanatory variable. For instance, it is theoretically expected that productivity of a block layer should not increase linearly with the number of porters assigned to a block layer, rather increase with an increase in the number of porters until appoint of diminishing returns is reached then productivity decreases. Therefore, there is a limit to which a block layer can best be served by porters to achieve higher productivity, hence the inclusion of the term for the square of the number of porters assigned to a block layer. Results showed that an experienced and skilled block layer needs three porters while the inexperienced and low-skilled one needs four porters to produce optimum output at any wall height. Secondly, whereas the level of education and experience were deemed to influence productivity individually, it would be difficult to isolate the effect of each since they are individual attributes that have a combined effect on the performance of an individual block layer and hence the inclusion of the interaction term between the level of education and experience. 
Figure 2 shows the scatterplots of the response variable and the respective predictor variables. There is a strong positive slope between productivity and three predictor variables namely, the number of porters assigned to a block layer, level of education of a block layer and a combination of the level of education and experience of a block layer. The wall height shows a strong negative slope with productivity and a weak negative slope exists with the square of the number of porters per block layer. The weak slope for the square of the number of porters per block layer could be a result of lack of internal variability in data for the variable. However, the negative slope confirms a-priori expectation that productivity decreases at an increasing rate with the number of porters assigned to a block layer. Lastly, the experience of a block layer gives no change in slope in comparison with productivity, showing that experience alone has no significant effect on productivity. The six variables were further explored for significance in model estimation.

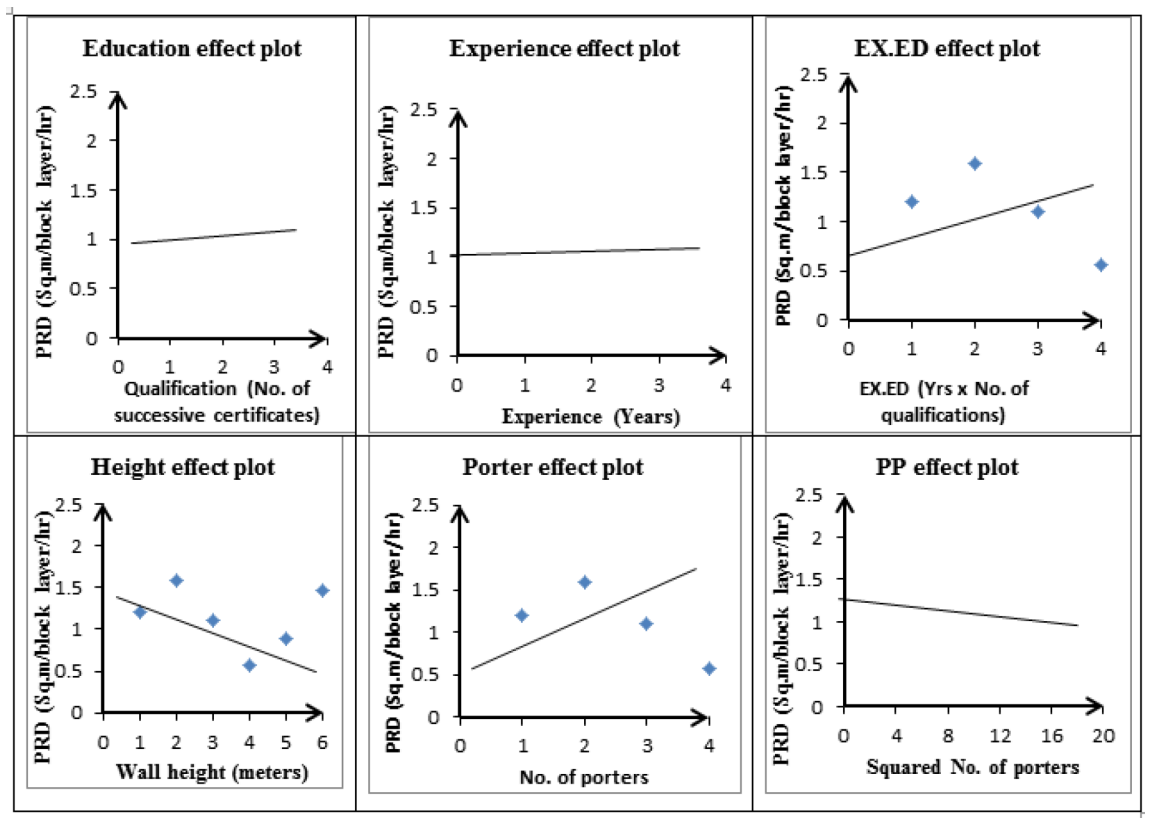

Note: PRD is productivity (sq. $\mathrm{m}$ per hour); $\mathrm{E}$ is experience of a block layer (less than five years $=0$, at least five years $=1$ ); ED is skill/education level of a block layer (no craft or diploma certificate =0, craft or diploma certificate $=1) ; \mathrm{H}$ is wall height $(\mathrm{m}) ; \mathrm{P}=$ Number of porters per block layer.

Figure 2. Scatterplots Showing Relationship between the Response and Respective Explanatory Variables

The response variable is a continuous random variable (productivity measured in sq. $m$ of wall built per hour) and therefore more best modelled using ordinary least squares linear regression-based a vector of explanatory variables (Kutner, Nachtsheim and Neter, 2004). The modelling approach adopted was the elimination of non-significant model variables based on the sign of the coefficient and strength of the $t$-value for $95 \%$ confidence level.

Table 3 gives a summary output of four estimated models. Model 1 included all the direct effects and second-order terms. The results show that only the wall 
height was significant at $95 \%$ confidence level. The signs of the coefficients were as a-priori expectation although not significant for most of the variables including the intercept. Specifically, the second-order terms yielded coefficients with signs conforming to a-priori expectation. Applying the elimination method, the secondorder term for square of the number of porters per block layer was removed during estimation of Model 2. The results yielded two significant variables: wall height and the number of porters per block layer, and the intercept. In Model 3, we further removed the direct effects of experience and level of education from the model due to its low p-values in both Models 1 and 2. The results show three explanatory variables of wall height, the number of porters per block layer and the combined effect of level of education and experience, as well as the intercept, was significant at $95 \%$ confidence level. In Model 4, only the square of the number of porters per block layer was returned to the model, without any improvements in comparison with Model 3.

The best-estimated model based on $R^{2}$ value, AIC value and significance of the model variables is Model 3 summarised here as follows:

PRD $=0.53-0.08 \mathrm{H}+0.40 \mathrm{P}+0.36$ EXED $\quad\left(R^{2}=0.65\right.$ and $\left.\mathrm{AIC}=51.16\right) \quad$ Eq. 3

Where, PRD is the productivity of block laying expressed in sq. $\mathrm{m}$ of wall built per hour per block layer using blocks of size $400 \mathrm{~mm} \times 225 \mathrm{~mm} \times 200 \mathrm{~mm}, P$ is the number of porters assigned to a block layer, $\mathrm{H}$ is the working height $(\mathrm{m})$ and EXED is the product of the level of education and experience of a block layer (equal to one for a block layer with at least five years' experience and a craft or diploma education level and zero for a product involving no education or less than five years' experience).

The results show that all the four estimated models are significant at $95 \%$ confidence level ( $p$-value < 0.05) confirming that indeed productivity of block laying is influenced by external factors as per a-priori expectation. The $R^{2}$ values of the four models are $64 \%$ and at most $65 \%$, showing that $35 \%-36 \%$ of the variability is still unexplained by the four models. Nevertheless, the results show models with the strong and reliable predictive ability of productivity of block laying on building sites with potential application in planning, budgeting and control of blockwork. However, there is still need for future research to explore incorporating more variables related to other attributes of the individual block layer and technologies available to the block layer to reduce on the unexplained variability in the current model. Secondly, further research should explore in detail direct effects of the experience of a block layer and ensure internal variability in data related to the number of porters assigned to a block layer than current data could explain. The best-estimated model based on $R^{2}$ value and significance of the model variables is Model 3 summarised in Equation 3. 


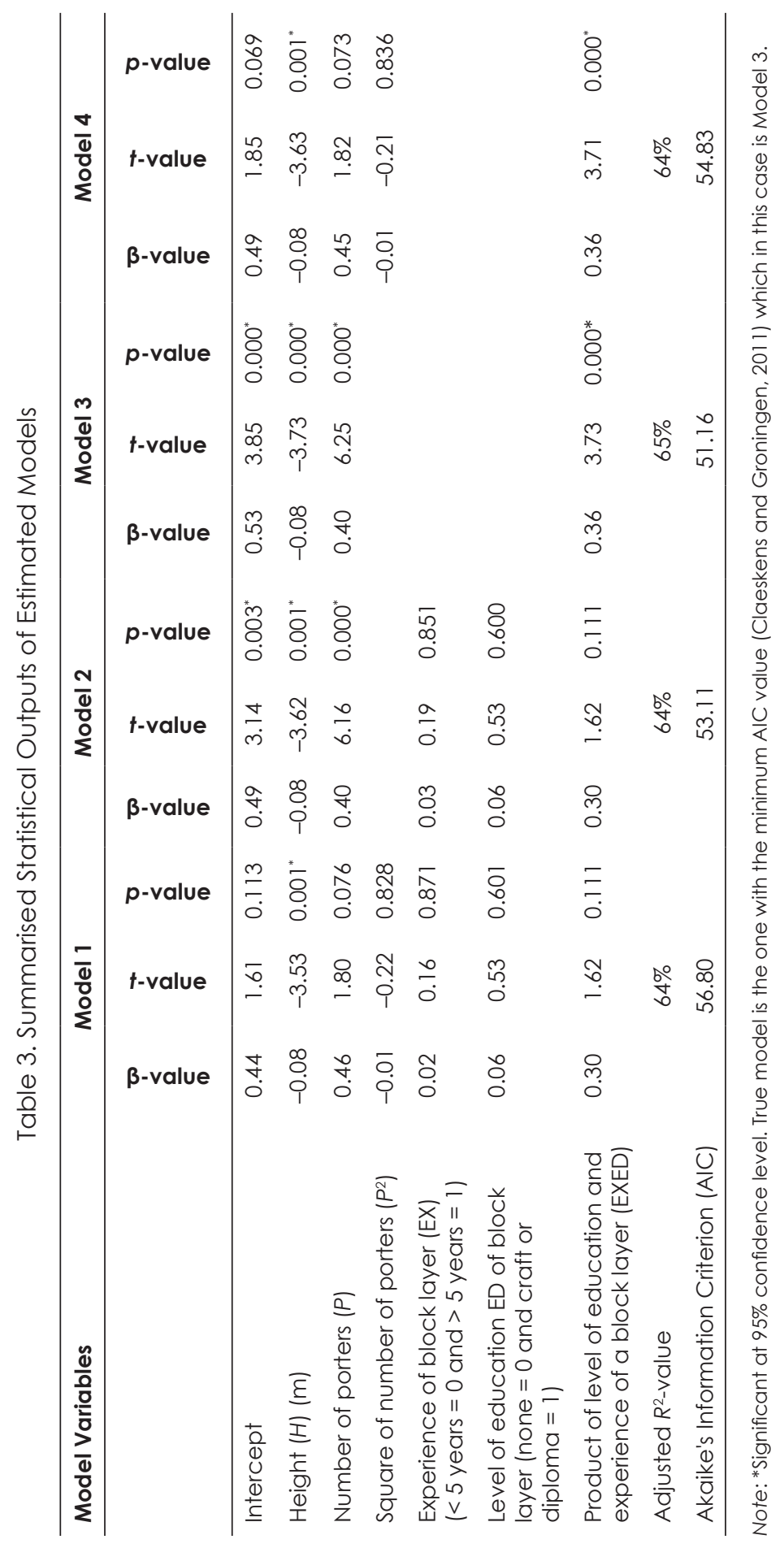




\section{DISCUSSION}

The results presented in this article show that productivity of block laying is influenced by external factors (work height and number of porters assigned) derived from the work environment and attributes of a block layer (internal factors). Specifically, the current study provides a framework for measuring productivity and model estimation based on a set of explanatory variables. Most significant factors include the working height, number of porters assigned to a block layer and a combined effect of experience and level of education of a block layer. These results provide an additional tool to project managers working in a labour-intensive construction industry to plan and schedule resources related to blockwork on building projects to minimise delays and cost overruns.

The model results show that whereas productivity reduces with work height, it possible to leverage productivity at heights by increasing the number of porters, a decision a project manager will have to make taking into account the cost. Figure $3(a)$ shows the sensitivity analysis of the model with productivity plotted against the working height considering none and up to three porters assigned to a block layer for the category of the educated and experienced block layers. From the figure it can be deduced for example, for work height of $3.50 \mathrm{~m}$, it is possible to increase block laying productivity from 1.0 to $1.40 \mathrm{sq} . \mathrm{m}$ per hour, which is a $40 \%$ increase if the project manager decides to increase the number of porters from one to two per block layer. This provides the project manager with an added tool to leverage productivity through efficient allocation of resources under time constraints and budget. Generally, for heights, block laying productivity is leveraged by increasing the number of porters assigned to a block layer. Almost productivity doubles for heights up to $5.50 \mathrm{~m}$ if a block layer is assigned three porters in comparison with one porter.

Figure 3(b) on the other hand relates block laying productivity for block layers with less than five years' experience and no craft or diploma certificate or with at least craft certificate and less than five years' experience. In comparison with Figure 3(a), the productivities are much lower irrespective of whether the block layer was assigned a porter or not. The effect is profound in a situation where the block layer is not assigned a porter, productivity decreases twofold at a height of $2.50 \mathrm{~m}$. This result alone demonstrates that it is better to have a block layer with minimum craft certificate and at least five years' experience for higher productivity. As such, basic training of a block layer is key to improved productivity in block laying and practice.

Block layers with no craft or diploma certificates or five years' experience require more porters to have higher productivity in comparison with the educated and at least five years' experience for the same work height. For instance, 0.85 sq. $m$ of blockwork can be achieved by a block layer with at least a craft or diploma certificate and five years' experience with no porter working at a height of $0.50 \mathrm{~m}$. The equivalent productivity is $0.89 \mathrm{sq} . \mathrm{m}$ which can be achieved for the same height for a block layer without a craft or diploma certificate and less than five years' experience assigned one porter. That is, a block layer without a craft or diploma certificate and less than five years' experience will require an additional porter to build the same sq. $m$ of the wall as a block layer with at least craft or diploma certificate and five years' experience working at the same height. 


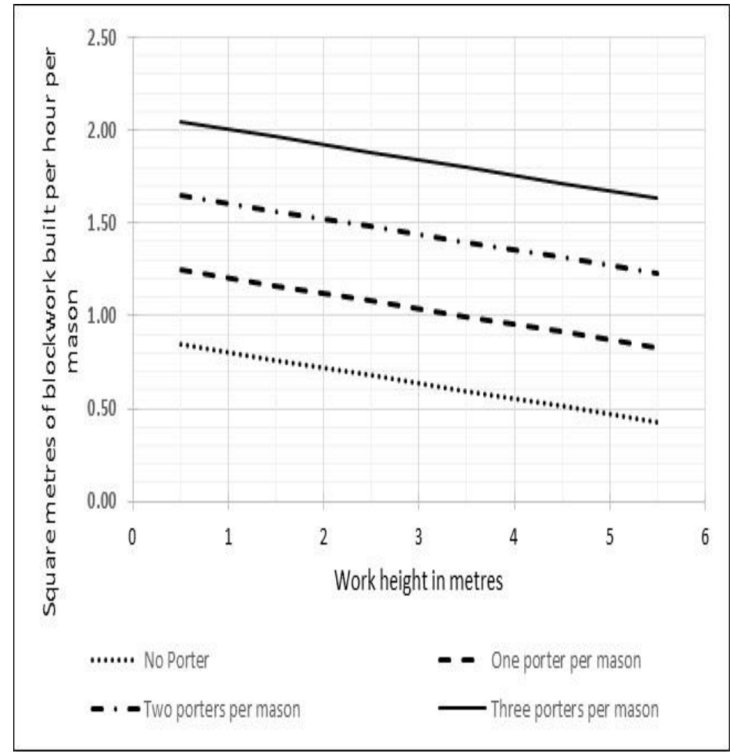

(a)

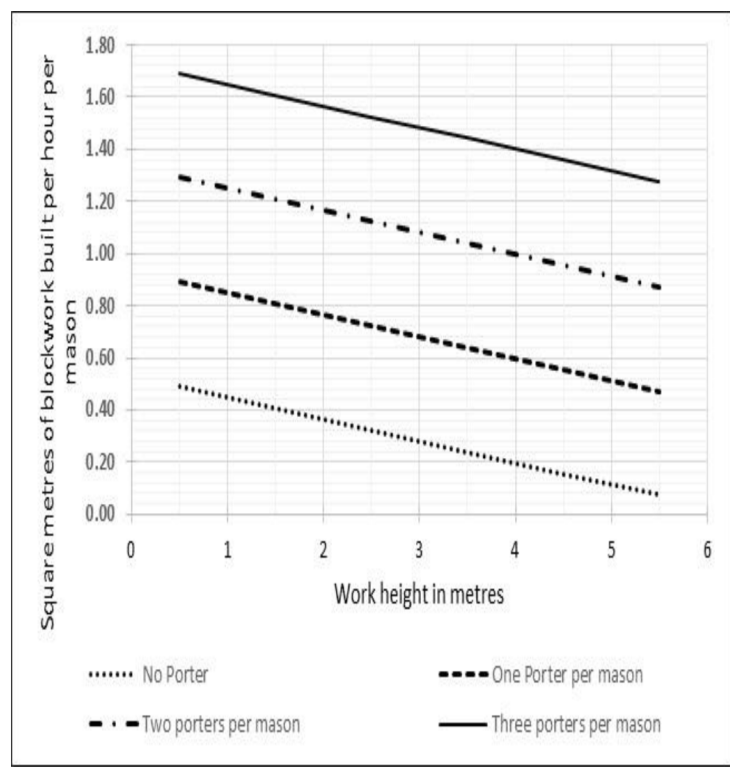

(b)

Figure 3. Sensitivity Analysis of the Estimated Model for (a) Experienced and Educated Block Layer and (b) Block Layer with No Education and Less than Five Years' Experience 
The model results show that whereas productivity reduces with work height, it is possible to leverage productivity at heights by increasing the number of porters, a decision a project manager will have to make taking into account the cost. Figure 3 (a) shows the sensitivity analysis of the model with productivity plotted against the working height considering none and up to three porters assigned to a block layer for the category of the educated and experienced block layers. From the figure it can be deduced for example, for work height of $3.50 \mathrm{~m}$, it is possible to increase block laying productivity from 1.0 to $1.40 \mathrm{sq}$. $\mathrm{m}$ per hour, which is a $40 \%$ increase if the project manager decides to increase the number of porters from one to two per block layer. This provides the project manager with an added tool to leverage productivity through efficient allocation of resources under time constraints and budget. Generally, for heights, block laying productivity is leveraged by increasing the number of porters assigned to a block layer. Almost productivity doubles for heights up to $5.50 \mathrm{~m}$ if a block layer is assigned three porters in comparison with one porter.

Figure $3(\mathrm{~b})$ on the other hand relates block laying productivity for block layers with less than five years' experience and no craft or diploma certificate. In comparison with Figure 3(a), the productivities are much lower irrespective of whether the block layer was assigned a porter or not. The effect is profound in the situation where the block layer is not assigned a porter, productivity decreases twofold at a height of $2.50 \mathrm{~m}$. This result alone demonstrates that it is better to have a block layer with minimum craft certificate and at least five years' experience for higher productivity. As such, basic training of a block layer is key to improved productivity in block laying and practice.

Block layers with no craft or diploma certificates or five years' experience require more porters to have higher productivity in comparison with the educated and at least five years' experience for the same work height. For instance, $0.85 \mathrm{sq}$. $\mathrm{m}$ of blockwork can be achieved by a block layer with at least a craft or diploma certificate and five years' experience with no porter working at a height of $0.50 \mathrm{~m}$. The equivalent productivity is $0.89 \mathrm{sq}$. $\mathrm{m}$ which can be achieved for the same height for a block layer without a craft or diploma certificate and less than five years' experience assigned one porter. That is, a block layer without a craft or diploma certificate and less than five years' experience will require an additional porter to build the same sq. $m$ of the wall as a block layer with at least craft or diploma certificate and five years' experience working at the same height.

\section{CONCLUSION AND FUTURE RESEARCH}

This study explored the concept of block laying productivity on building sites in the labour-intensive construction industry. Productivity was defined as the hourly area of wall built by a block layer taking into consideration the working height, level of education and experience taken at five years threshold. The data used in the study was collected from 40 building sites in Kampala, Uganda. The data collection method was an observational study measuring the work output and attributes of the block layer and work environment defined by height and number of assigned porters. The results show that block laying productivity per block layer decrease with work height and that there is high variability amongst block layers. A linear regression model is proposed and estimated for productivity taking into account the working height, number of assigned porters to a block layer and a combination of the level 
of education and experience of a block layer. The model is statistically significant at $95 \%$ confidence level and predicts $65 \%$ of the variability in productivity. The results of the current study clearly show that education and experience are important for higher productivity and that for any uneducated and less experienced block layer, you need an extra porter to return the same productivity. These results provide an additional tool to a project manager involved in blockwork on building sites to plan, schedule and control resources to fit within budget and project duration especially in labour-intensive construction industries found in developing countries.

However, the current study could be extended in the future to address key issues that would improve the predictive ability of the current model for which there was no sufficient empirical data. For instance, the number of porters assigned to a block layer was mostly two for 44 observations out of a sample size of 70 . This lack of internal variability in the data meant that the a-priori expectation of productivity increasing at a decreasing rate with the number of porters assigned to a block layer was not significant. The second-order term for square of the number of porters assigned to a block layer had a negative sign which is consistent with a-priori expectation but not significant at $95 \%$ confidence level. Secondly, the direct effects of level of education and experience were not significant in the model, suggesting that education or experience alone counts less on the productivity of block laying. Although the signs of the coefficients are positive as per a-priori expectation, they were not statistically significant individually. This result needs to be explored further in a different environment than Kampala. Thirdly, there is a need to explore the effect of technologies used in mortar mixing and transportation and tools used by a block layer on productivity. These could have a significant impact on productivity but due to lack of variability in data collected in this study, it was not possible to conclude on these factors. Lastly, there is a need to explore the effect of outside environment on productivity of a block layer. That is a block layer working in a shade as opposed to open space under direct sunlight. This would help explain, whether block layers work better under shades for which these would have to be provided as part of an improved work environment.

\section{ACKNOWLEDGEMENTS}

The authors would like to thank the site engineers at different building sites that provided the researcher permission to gain access to the sites and collect data used in the study.

\section{REFERENCES}

Alinaitwe, H.M. (2008). Improvement of labour performance and productivity in Uganda's building industry. PhD diss., Lund University.

Alinaitwe, H.M., Mwakali, J.A., Hansson, B., Alinaitwe, H.M., Mwakali, J.A. and Hansson, B. (2007). Factors affecting the productivity of building craftsmen: Studies of Uganda. Journal of Civil Engineering and Management, 13(3): 169176. https://doi.org/10.3846/13923730.2007.9636434. 
Apolot, R.E. (2009). Investigation into the causes of delay and cost overruns in construction projects in Uganda public sector: Case of civil aviation authority. PhD diss., Makerere University.

Chigara, B. and Moyo, T. (2014). Factors affecting labor productivity on building projects in Zimbabwe. International Journal of Architecture, Engineering and Construction, 3(1): 57-65. https://doi.org/10.7492/IJAEC.2014.005.

Chudley, R. and Greeno, R. (2010). Building Construction Handbook. 8th Ed. Oxford: Elsevier Ltd.

Claeskens, G. and Groningen (2011). Model Selection and Model Averaging. Cambridge: Cambridge University Press.

Dai, J., Goodrum, P.M. and Maloney, W.F. (2009). Construction craft workers' perceptions of the factors affecting their productivity. Journal of Construction Engineering and Management, 135(3): 217-226. https://doi.org/10.1061/ (ASCE)0733-9364(2009) 135:3(217).

Florin, P.C., Alexandru, M., Maria, M. and Andrea, L. (2017). Models of development of labour productivity forecast. Romanian Statistical Review, 65(4): 107-1 14.

Green, S.B. (1991). How many subjects does it take to do a regression analysis? Multivariate Behavioral Research, 26(3): 499-510. https://doi.org/10.1207/ s15327906mbr2603_7.

Hafez, S.M., Aziz, R.F., Morgan, E.S., Abdullah, M.M. and Ahmed, E.K. (2014). Critical factors affecting construction labor productivity in Egypt. American Journal of Civil Engineering, 2(2): 35-40. https://doi.org/10.1 1648/j.ajce.20140202.14.

Irumba, R. (2014). Spatial analysis of construction accidents in Kampala, Uganda. Safety Science, 64: 109-120. https://doi.org/10.1016/j.ssci.2013.11.024.

Jang. H., Kyonghoon, K., Hyung, J.K. and Jaejun, K. (2011). Labour productivity model for reinforced concrete construction projects. Journal of Construction Innovation, 11(1): 92-113. https://doi.org/10.1108/14714171111104655.

Kuroshi, P.A. (2014). Study of internal factors affecting labour productivity in medium size construction firms in Nigeria. International Journal of Education and Research, 2(12): 83-92.

Kutner, M.H., Nachtsheim, C.J. and Neter, J. (2004). Applied Linear Regression Models. 4th Ed. New York: McGraw-Hill Publishing Inc.

Makulsawatudom, A. and Emsley, M. (2001). Factors affecting the productivity of the construction industry in Thailand: The project managers' perception. Paper presented at the 17th Annual ARCOM Conference. University of Salford, Salford, 5-7 September.

Ministry of Works and Transport (2012). Standard Specifications Draft for Construction Sector. Kampala, Uganda: Government of Uganda.

Mostafa, E.S. and Khaled, M.E. (2011). Towards improving construction labor productivity and projects' performance. Alexandria Engineering Journal, 50: 321-330. https://doi.org/10.1016/j.aej.2012.02.001.

Muhammad, Z.M. and Rosli, M. (2016). Site layout design that ensures the efficiency at construction sites. Available at: http://civil.utm.my/wpcontent/uploads/2016/12/Site-Layout-Design-That-Ensures-the-Efficiency-atConstruction-Site.pdf.

Nalumansi, J. and Mwesige, G. (2011). Determining productivity of Masons for both stretcher and header bonding on building sites. Paper presented at the $2 \mathrm{nd}$ International Conference on Advances in Engineering and Technology: Contribution of Scientific Research in Development. Entebbe, Uganda. 
Ng, S.T., Skitmore, R.M., Lam, K.C. and Poon, A.W.C. (2004). Demotivating factors influencing the productivity of civil engineering projects. International Journal of Project Management, 22(2): 139-146. https://doi.org/10.1016/S02637863(03)00061-9.

Srinavin, K. and Mohamed, S. (2003). Thermal environment and construction workers' productivity: Some evidence from Thailand. Journal of Building and Environment, 38(2): 339-345. https://doi.org/10.1016/S0360-1323(02)00067-7.

Sweis, R.J., Sweis, G.J., Hammad, A.A.A. and Rumman, M.A. (2009). Modeling the variability of labor productivity in Masonry construction. Jordan Journal of Civil Engineering, 3(3): 197-212.

Syverson, C. (2011). What determines productivity? Journal of Economic Literature, 49(2): 326-365. https://doi.org/10.1257/jel.49.2.326.

Thiyagu, C. and Dheenadhayalan, M. (2015). Construction labor productivity and its improvement. International Research Journal of Engineering and Technology, 2(8): 824-832.

Thomas, V. and Sudhakumar, J. (2014). Factors influencing construction labour productivity: An Indian case study. Journal of Construction in Developing Countries, 19(1): 53-68.

Uganda Bureau of Statistics (2016). Construction Sector Indices, June 2016. Kampala, Uganda: Statistics House.

Uganda National Commission for UNESCO (2013). Uganda and UNESCO, Annual Information Magazine 2012/2013. Madagascar: Editorial Staff of the National Commissions for UNESCO and Editions Afrique Océanie. Available at: http:// natcomreport.com/ [Accessed on 1 August 2016].

Voorhis, C.R.W. and Morgan, B.L. (2007). Understanding power and rules of thumb for determining sample sizes. Tutorials in Quantitative Methods for Psychology, 3(2): 43-50. https://doi.org/10.20982/tqmp.03.2.p043. 


\section{APPENDIX}

\section{Combined Questionnaire and Measurement Sheet}

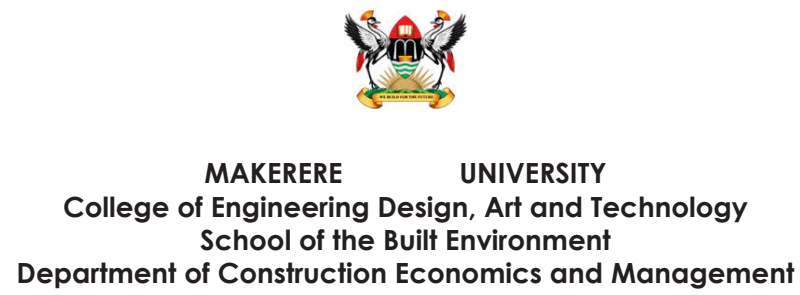

\section{Introduction}

This research instrument has been prepared for the study of "Productivity of Block on Building Site in Kampala". This study is not in any way an appraisal of your activities but it is meant strictly for academic purposes. Thus, any information provided will be treated as confidential and used only for the stated purpose. The instrument comprises two parts: a questionnaire and a measurement sheet designed to collect data on block laying output per day and it is administered on-site by properly identifiable enumerators with the University Identity Cards.

Project Name:

Date:

Site Location: (a) Village/Cell

(b) Division

\section{Part A: Attributes of a Block layer}

1. Gender (Tick appropriately)

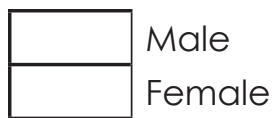

2. How long have you been in the construction business?

\begin{tabular}{|l|l}
\hline & Less than one year \\
One to five years \\
Six to 10 years \\
Over 10 years
\end{tabular}

3. Highest qualification in the field of speciality (Tick one)

\begin{tabular}{|l|l}
\hline & Craft certificate \\
Diploma & \\
Bachelor's degree & \\
Other (specify)
\end{tabular}


Allan Dickens Ouga et al.

Part B: Measurement of Daily Block Laying Output

1. The number of porters assigned:

2. Wall height (Tick appropriate range)

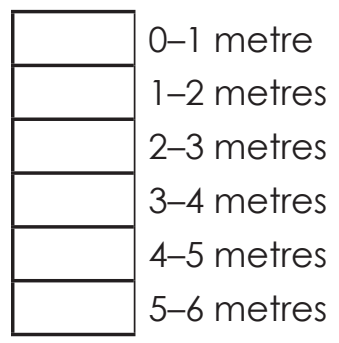

3. Work start time:

4. Time for health breaks:

a. Health break 1; from to

b. Health break 2; from to

3. Work end time:

4. The area in square metres built:

END

THANK YOU 